\title{
A304＼cjkstart風誘因による層状液体流れの観測結果
}

\author{
本間 亮(東海大学)，大山 龍一郎(東海大学)
}

\section{Experimental Observation of Wind Induced Flow in Stratified Liquid}

\author{
Ryo Homma, Ryu-ichiro Ohyama
}

Tokai University

\begin{abstract}
We have been researched on the velocity field measurements of gas-liquid interface EHD flow phenomenon. This is the unique phenomenon of which the flow of the electrically-charged fluid behavior is induced inside the liquid, when corona discharge is caused for the gas-liquid interface. Generally, EHD wind called the ion wind blows, when corona discharge is generated in the gas phase. Then, the flow field which resembled flow phenomenon done the inducement under gas phase corona discharge very well was able to be observed, when the wind which simulated the ion wind for this gas-liquid interface was blown. This paper describes PIV measurements of the wind induced flow in stratified liquid. The velocity fields of the wind induced flow are successfully obtained by means of the flow visualization technique and the PIV technique..
\end{abstract}

Keywords: Visualization, PIV, Ion Wind, EHD Flow, and Gas-Liquid Interface

\section{1. はじめに}

著者らは従来から気相コロナ放電によって誘起 する気体と誘電液体の界面電気流体力学現象につ いて研究を行っている(1)(2)。この現象は，気体液 体界面に向けてコロナ放電を起こすと，液体中に 電気流体的な振る舞いの流動が誘起されるニニー クな現象である。このとき，気体液体界面にはい くつかの運動力による効果が生じているものと考 えられるが，これらの効果は実験的に分離して観 測することが困難である。そこで，本研究ではコ ロナ放電時に生じるイオン風の効果について着目 している。

一般に，気相でコロナ放電が生じると，イオン 風と呼ばれる電気流体力学的な風が吹く。この気 体液体界面に向けてイオン風を模擬した風を吹き 付けたところ，気相コロナ放電下で誘因する流れ 現象と極めてよく似た流れ場が観測できた。本研
究ではこの模擬イオン風による流れ場の可視化と PIV 法を用いた解析を行った。

本報はこの風誘因による層状流れを観測した結 果について示すとともに，PIV 法を用いて速度分 布を測定した結果について報告する。

\section{EHD 流動}

Fig.1 は気相コロナ放電によって誘起する誘電 液体内の EHD 流動を可視化し, PIV 処理した結 果である(1)。EHD 流動は針電極近傍でその流れ 場を形成し，針電極を軸に誘電液体中に 3 次元軸 対称な渦流を形成している。この EHD 流動の発 生原因は, コロナ放電電極からのイオン風, 荷電 粒子のドラッグ力, 液体分子自体の分極電荷など 複数の力効果が生じていると考えられる。Fig.2 
は本 $\mathrm{EHD}$ 流動について推測される発生メカニズ ムを図式的に表している。本研究では，EHD 現 象の発生メカニズムの整理のために，イオン風が 流れ場に与える影響を検討するために，イオン風 を模擬した風の誘電液体界面一の吹き付けによる 液体内部の流動について観測することとした。

\section{3. 実験方法}

Fig.3 は本実験装置の概略を示している。実験 装置は誘電液体を満たしたアクリル容器, ノズル, 水銀ランプ, CCD カメラ, および PC から構成 される。本実験では作動誘電体としてシリコンオ イルを用いた。シリコンオイルは容器内に液位 $30 \mathrm{~mm}$ を満たし，液体表面から $3 \mathrm{~mm}$ 上方に円筒 状のノズル(内径 $4 \mathrm{~mm}$ )を設置する。誘電液体内に はノズルから液体界面に吹き付けられる風によっ て 3 次元軸対象な流れ場が発生する。この流れ場 は誘電液体内にトレーサ粒子としてアルミ粉を䀣 濁し，側面から $250 \mathrm{~W}$ 水銀ランプのシート光を照 射することで2 次元平面に可視化した。撮影は， ンインターレスモノクロ CCDカメラPhotocam120 を用い，フレームグラバボードを通してコンピュ 一タ内に画像を取得した。PIVにおける画像計測 は，時間間隔 $\mathrm{t}=2 / 60[\mathrm{sec}]$ の可視化画像を PC に取 り込み，濃度相関法(3)によってトレーサ粒子の速 度ベクトル分布を求めた。実験には，粘度の異な る 1，5，10，および 50cSt シリコンオイルを用 いた。これらは粘性以外の物性值でほぼ同様な性 質を持ち，実験条件を同条件とすることで比較さ れる。

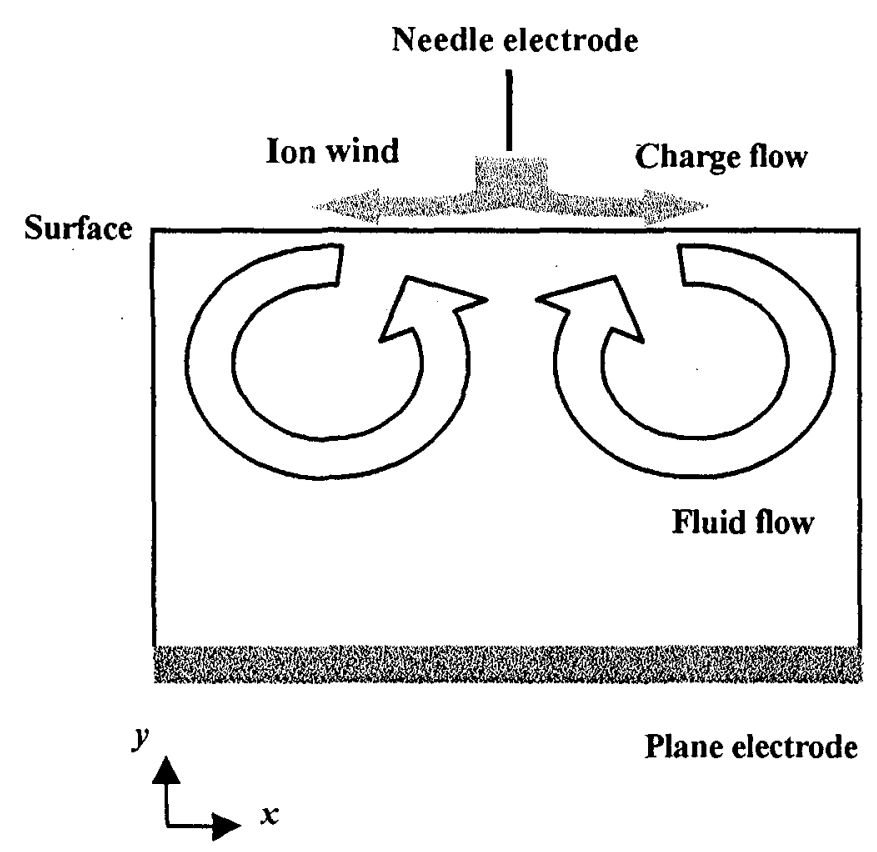

Fig2 Estimation of present type EHD phenomenon

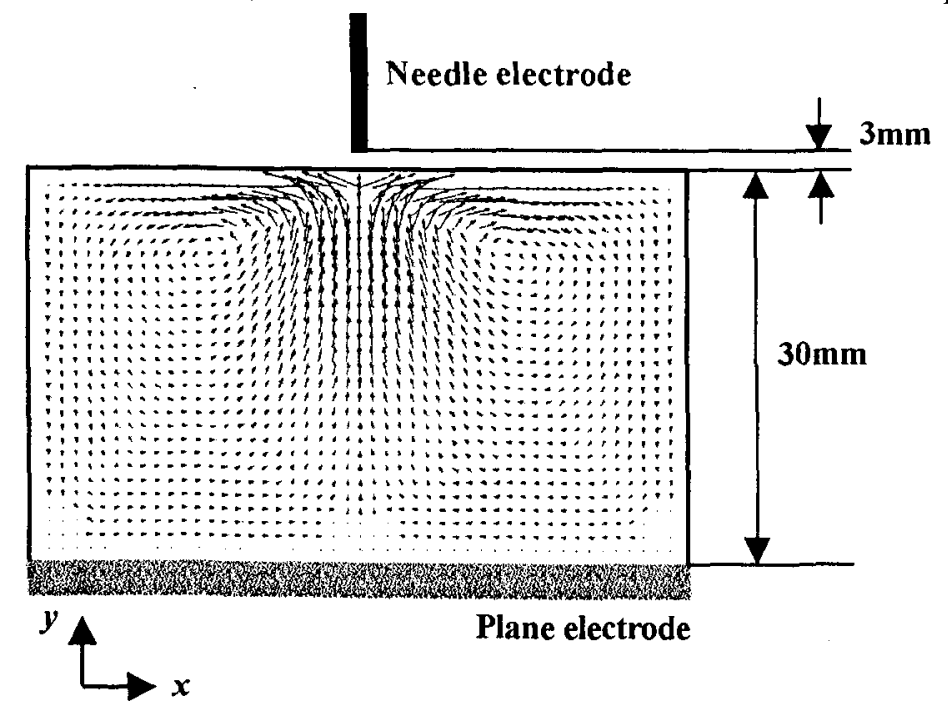

Fig1 Velocity fiedl of present type typical EHD phenomenon
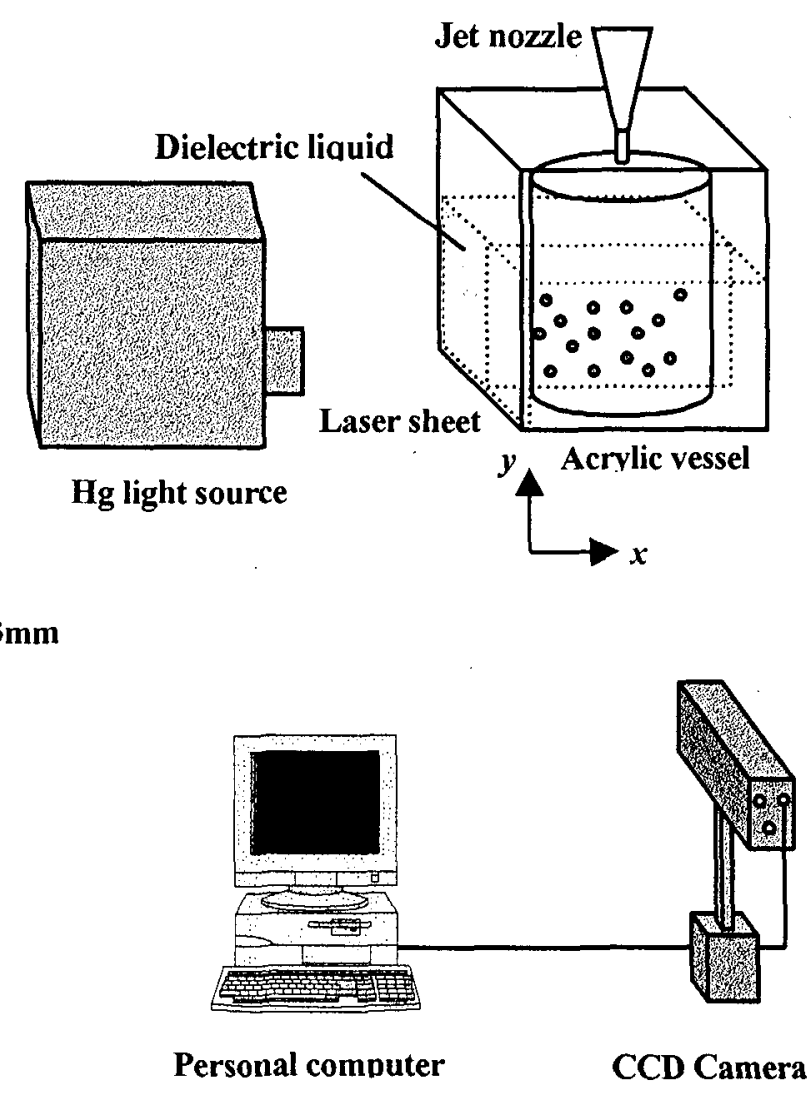

Fig.3 Experimental setup 


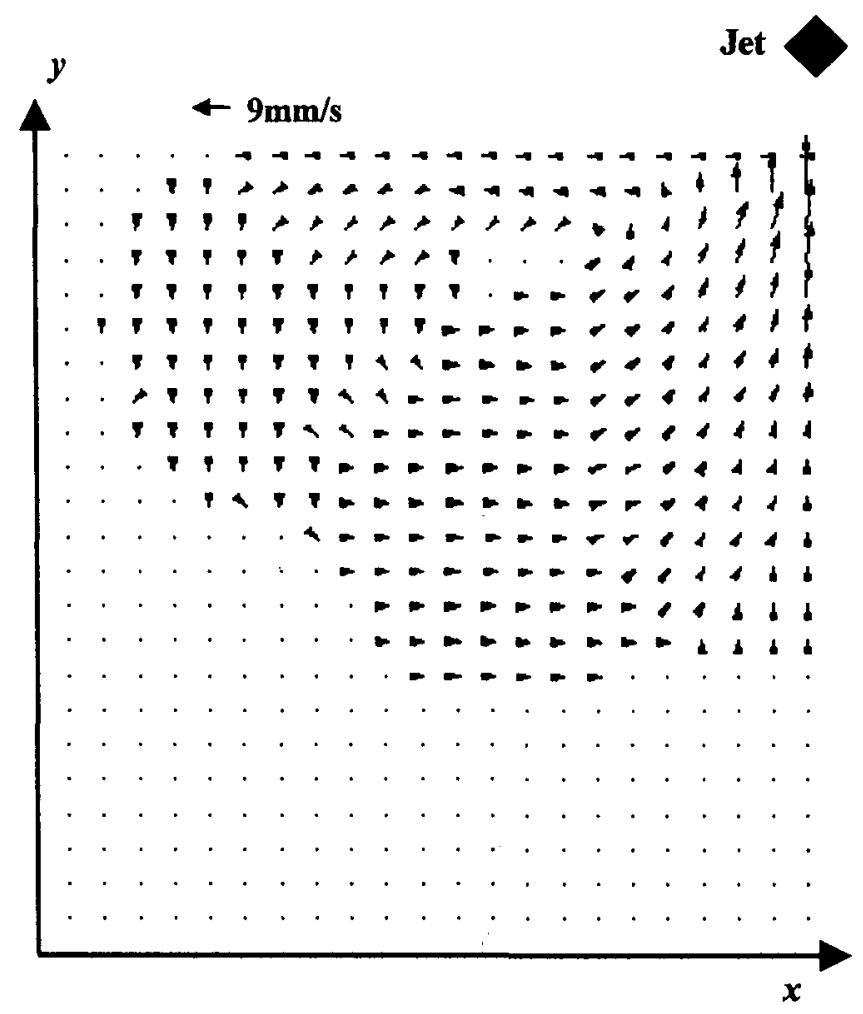

(a) 50cSt silicone oil

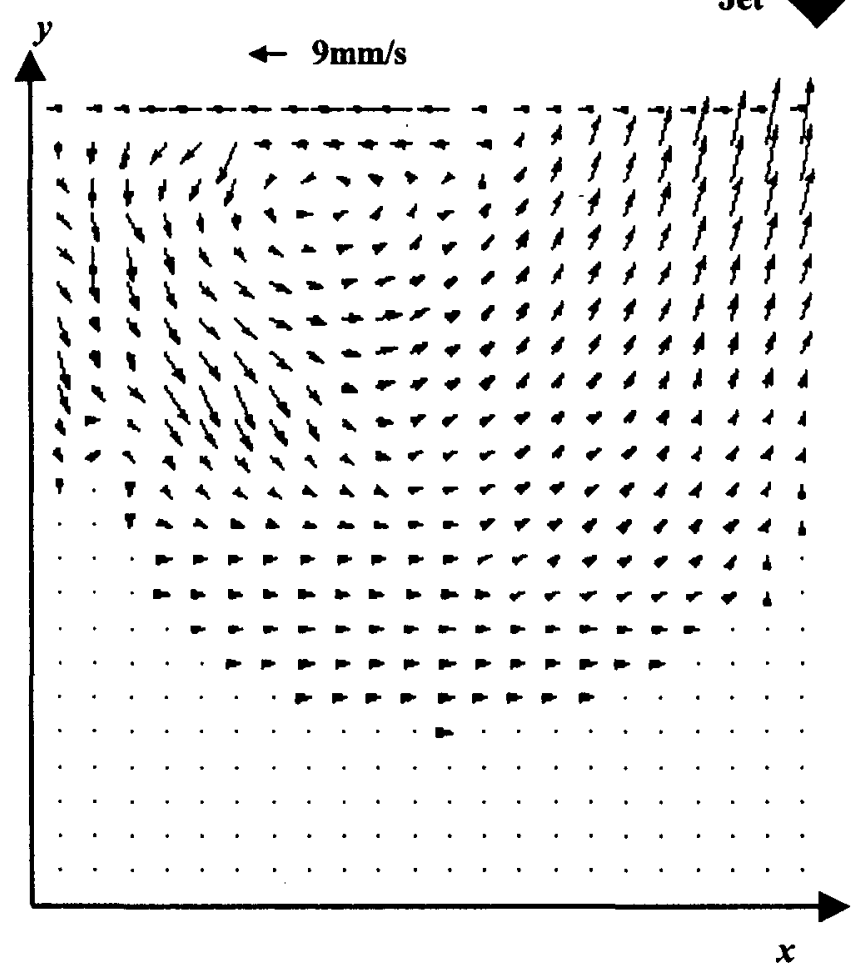

(c) $5.0 \mathrm{cSt}$ silicone oil

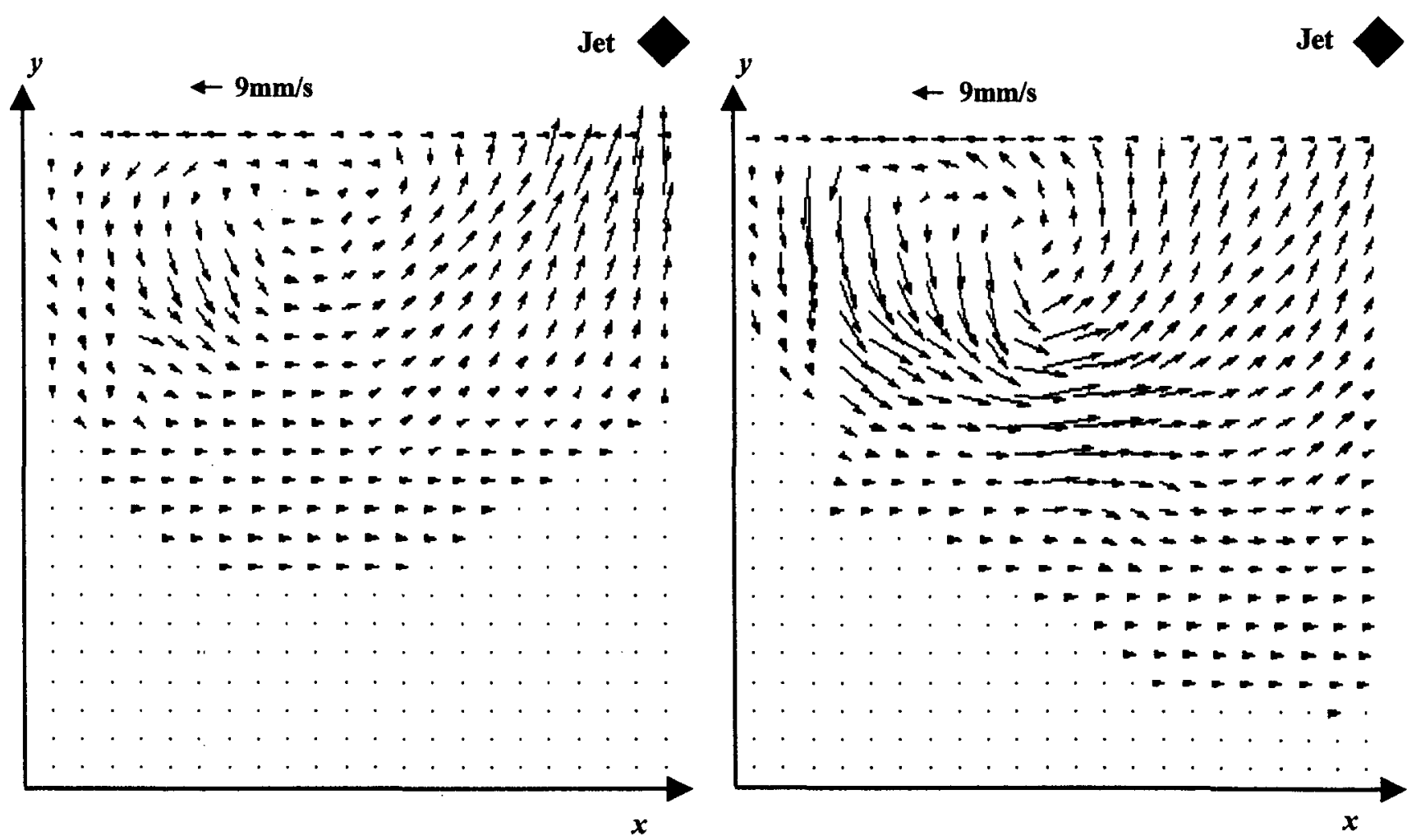

(b) $10 \mathrm{cSt}$ silicone oil

(d) 1.0eSt silicone oil

Fig.4 Velocity fields of 50cSt obtained by PIV 


\section{4. 実験結果}

Fig.4(a)は 50cSt シリコンオイルを用いた場合の PIV 測定結果である。ノズルからは流量 $50.5[\mathrm{ml} / \mathrm{min}]$ の風を液体界面に吹き付けている。 本実験における流れ場は, Fig.1に示した EHD 流 場と同様に左右対称の流れであるために，ここで は左半面の流れ場だけを示している。誘電液体内 の流れ場は，ノズル直下から壁面に向かっている。 その後, 流れは深層に向かい, 流れの連続性から 再び夜面に循環している。流れの速度はノズル直 下においてもつとも速く，側壁に向からにつれて 低速になる。液面速度は, 渦流の中心の真上に近 づくにつれ速くなり，そこからは減速する。壁面 側ならびに深層に揖て速度はほとんど0となる。 な㧍，ノズル直下では液面の歪みにより液面速度 は推定できない。

Fig.4(b)は 10cSt シリコンオイルを用いた場合の PIV 測定結果である。50cSt シリコンオイルの流 れと比較すると, 渦流中心が側壁側に移動し, 流 れ場領域が変化していることがわかる。Fig.4(c) は 5cSt シリコンオイルを用いた場合の PIV 測定 結果である。粘性を下げるとさらに渦流中心が側 壁側に移動し, 流れ場領域が液体内部全体に広が っていることがわかる。Fig.4(d)は 1cSt シリコン オイルを用いた場合の PIV 测定結果である。流 れ場は側壁側の渦流付近でもつともはやい。流れ 場領域はさらに全体に広がり，他の粘性の PIV 処理結果に比べて非定常性が高くなった。

\section{5. 责察}

本実験では，誘電液体界面に吹き付けた模擬入 オン風にようて液体内には EHD 流動と類似した 流れ場が観測できた。この流れ場は中心軸を対象 に放射状に気液界面に沿って進展し, 容器の側壁 で液体内に入り込んで渦流を形成した。これはノ ズルから液体界面に吹き付けられる風が，液体界 面において放射状に広がり，その際に液体分子を 引きずるドラッグ力により生じたものと考えられ る。

粘性の異なるシリコンオイルを比較した場合, 粘性が低くなるにつれ渦流は側壁側に移動し, 流 れ場の領域も広がった。また比較的高い粘度のシ リコンオイルを用いた場合は，針電極を中心とし
た左右対称の定常流であったのに対し， lcSt の シリコンオイルのような比較的低粘度のシリコン オイルを用いた場合は三次元的要素の複雑な流れ 場になった。これらの結果は EHD 流れ場を観測 した結果と極めて類似したものとなった。すなわ ち, EHD 流動の発生にはコロナ風による液体分 子へのドラッグ力が梁く関わっていると考えられ る。

\section{6. まとめ}

本実験は，誘電液体界面にイオン風を模擬した 風を吹き込み，誘電液体内部に生じる流れ場を対 象に PIV 処理を行ったものである。この結果, 気相コロナ放電下で誘因する流れ現象と極めてよ く似た流れ場が観測できた。また，粘性の変化に 対する流動パターンの違いについて把握した。こ れらの結果から, 従来, 本研究において対象とし てきた EHD 流動の発生にはコロナ風による液体 分子八のドラッグカが深く関わっている知見を得 ることが出来たと考えられる。

\section{参考文献}

(1)R.Ohyama and K.Kaneko:Trans.IEEofJapan,

Vol.118-A,No.6,pp.743-744(1998)

(2)関野·大山・金古:可視化情報学会誌

Vol.18Suppl.,No.1,pp.117-120(1998)

(3)加賀·井上·山口：可視化情報学会誌

Vol.14,No.53,pp.38-45(1994) 